\title{
LETTER FROM THE DIRECTOR
}

I am proud to salute the $26^{\text {th }}$ edition of Policy Perspectives, the Trachtenberg School of Public Policy \& Public Administration's superb student journal. For 26 years our students have written and edited a journal of research related to public policy and public administration that addresses timely and important issues. Their work certainly embodies our school's motto of "doing good and doing it well."

Articles in this issue address critical policy issues both in the United States and in countries across the world, including Colombia, Argentina, and Chile. Our authors compare policy outcomes across American states and across countries and they apply a social equity lens to important issues that affect the most disadvantaged in our society. In their research, they superbly apply a variety of research methods, including behavioral economic analysis and cost-benefit analysis, as well as qualitative methods —making our school look good!

The health and well-being of the most disadvantaged is addressed by Ahoefa Ananouko in her examination of proposed changes to the food stamp program, by Isabella Higgins in her analysis of the gaps in maternal health care for women in rural areas across our country, and by Hernando Grueso-Hurtado in his exploration of policies to address mercury pollution resulting from gold mining in Colombia.

Threats to the economic well-being and privacy of all are addressed by many authors. Elisa Walker examines social security privatization schemes in Argentina, Chile, and the United States; Matthew Pickering studies the impacts of Philadelphia's property tax abatement policy; and Maggie Smith analyzes consumer behavior in the market for smartphone apps to explore ways to safeguard privacy. McCall Hopkin focuses on policy that hits close to home in her analysis of student behavior in accessing various financial aid options. And Haley Dunn addresses an extremely timely issue in her costbenefit analysis to assess the effects of marijuana legalization on society.

This volume also includes two interviews with Trachtenberg School alumni working in various capacities and subsectors of the public policy and public administration field, as well as three of the outstanding blog posts that first appeared on www.policyperspectives.org, the blog associated with the Policy Perspectives student media.

We take great pride in the Policy Perspectives blogs and the GW Wonkcast, the studentrun podcast also produced as part of Policy Perspectives. I encourage you to download an episode from iTunes or your favorite podcast source. 
The research of our students is available free of cost for public servants and fellow researchers via the journal, blogs and podcasts. We hope you enjoy this print copy of the journal and read the articles from this issue and past issues on Google Scholar or on the www.policy-perspectives.org website.

\section{Kathryn Newcomer, PhD}

Director

The Trachtenberg School of Public Policy and Public Administration 